\title{
Metode Tuning Operating Range Fuzzy PID Controller pada Sistem Orde Tiga
}

\author{
Nana Sutarna ${ }^{1}$ dan Bernadeta Siti Rahayu Purwanti ${ }^{2}$ \\ Jurusan Teknik Elektro, Politeknik Negeri Jakarta \\ Jl. Prof. Dr. G.A. Siwabessy, Kampus UI, Depok, 16425, Indonesia \\ nana.sutarna@elektro.pnj.ac.id ${ }^{1}$,rahayu.purwanti@elektro.pnj.ac.id ${ }^{2}$
}

\begin{abstract}
This research discusses the development of a model Fuzzy Proportional, Integral, Derivative (Fuzzy PID) controller models and self-tuning. This method has been implemented in the third-order system of Differential Equations, as a sample implementation of a PID controller. The methods self-tuning known are fuzzy rules, membership function (MF), and scaling factor. The focus of the discussion in this research is to introduce self-tuning to the operating range (OR) setting of MF. Previous research has succeeded in converting a PID controller to a Fuzzy Logic Controller (FLC) which is in accordance with the PID structure. The FLC has three inputs and one output as in the PID controller, hereinafter referred to as Fuzzy PID controller. Knowledgebase on the FLC structure of three inputs one output is expressed in the form of cubic fuzzy associative memory (FAM). The conversion was done by mapping errors, integrals error, derivative errors and outputs of PID controller into the OR of MF Fuzzy input/output. The size of the OR conversion val ue on the MF fuzzy input was set, so the response transient is set-to-point. While the OR value of the MF fuzzy output was fixed as a limitation. Improved settling time was reached up to $75.3 \%$ and percent overshoot was reduced by $57.7 \%$ in Fuzzy PID with PID controller. The output signal from the Fuzzy PID controller showed the smallest amplitude of 24.12, while the PID controller was 32.53. The amplitude unit depends on the Fuzzy PID controller parameters when it applied the real plant. The third-order Fuzzy PID controller has been successfully simulated in Simul ink/Matlab.
\end{abstract}

Keywords- PID, Fuzzy PID, operating range, third order system

\begin{abstract}
Abstrak- Riset ini membahas pengembangan model Fuzzy Proportional, Integral, Derivative (Fuzzy PID) controller dan self-tuning. Metode tersebut telah diimplementasikan pada sistem orde tiga dari persamaan Diferensial, sebagai sampel implementasi PID controller. Metode self-tuning yang dikenal adalah fuzzy rules, membership function (MF), dan scaling factor. Fokus pembahasan pada riset ini memperkenalkan selftuning pada pengaturan operating range (OR) dari MF. Penelitian sebelumnya telah berhasil mengonversi PID controller ke Fuzzy Logic Controller (FLC) yang strukturnya sesuai dengan PID controller. FLC yang dimaksud dengan tiga in put satu output seperti pada PID controller yang selanjutnya disebut Fuzzy PID controller. Knowledgebase pada struktur FLC tiga in put satu output dinyatakan dalam bentuk kubik fuzzy associative memory (FAM). Konversi yang dilaku kan dengan pemetaan error, integral error, derivative error dan output PID controller ke dalam OR dari MF Fuzzy in put/output. Besar kecilnya nilai konversi OR pada MF input fuzzy diatur sedemikian rupa hingga response transients sesuai set point. Sementara nilai OR dari MF fuzzy output dibuat tetap sebagai batasan. Perbaikan settling time tercapai hingga $75,3 \%$ dan percent overshoot berkurang sebesar $57,7 \%$ pada Fuzzy PID controller dengan pembanding PID controller. Sinyal output dari Fuzzy PID controller menunjukkan amplitudonya paling kecil 24,12, sedangkan PID controller adalah sebesar 32,53. Satuan amplitudo bergantung pada parameter-parameter Fuzzy PID controller, bila direalisasikan real plant. Fuzzy PID controller orde tiga telah berhasil disimulasikan dalam
\end{abstract} Simulink/Matlab.

Kata kunci-PID, Fuzzy PID, operating range, sistem orde tiga

\section{PENDAhUluaN}

Teknik tuning sudah banyak diteliti, namun masih terbuka luas peluang pengembangannya. Utamanya pada sistem kontrol Proportional Integral Derivative (PID) dengan berbagai pengembangan teknik tuning-nya. Salah satu pengembangan tersebut dengan metode tree physiology optimization (TPO) yang diimplementasikan [1] pada Proportional-Integral (PI). Teknik tuning lainnya adalah selftuning Fuzzy Logic Controller (FLC) on-line dengan mengatur fuzzy control rules [2], [3]. PID controller juga dapat di-tuning oleh FLC adaptive dengan pengaturan bentuk Membership Function (MF) [4]. Self-tuning fuzzy [5] dan fuzzy inference rule [6] telah diimplementasikan pada tuning PID controller. Seluruh teknik tuning menargetkan performa respon transien yang terlihat pada settling time, rise time, percent overshoot, dan error steady state [7].

Tuning parameter PID pada tiga variabel bebas mempengaruhi sinyal keluaran sistem. Tuning sebuah sistem PID controller sulit, jika salah setting parameter 
mengakibatkan respon transien yang buruk. Oleh karena itu untuk menghindari buruknya respon, perlu teknik tuning. Salah satu teknik tuning adalah Ziegler-Nichols [8]. Peneliti [9] telah mengembangkan teknik tuning PID controller dengan relay auto-tuning (RA). Peneliti [10] menggunakan teknik optimization algorithm untuk melakukan tuning PID controller. Hasilnya menunjukan teknik tuning optimization algorithm lebih ungguldibanding metode klasik.

Pada FLC, prosedur standar untuk teknik tuning belum ada. Metode teknik tuning pada FLC masih terus berkembang. Teknik tuning sederhana pada FLC menggunakan metode trial and error. Tuning pada bentuk MF dilakukan dengan mengubah dari bentuk simetris ke asimetris [2], [11]. Tuning pada fuzzy rules dilakukan dengan pengaturan consequence dan antecedent terhadap output fuzzy [12] - [14]. Tuning pada fuzzy controller juga dapat dilakukan dengan metode lain seperti scaling factor [15], [16]. Se mentara Operating Range (OR) dari MF input/output hanya dibatasi pada angka tertentu saja. Sehingga menjadi sebuah pemahaman yang mutlak bahwa OR dari MF input/output tidak bisa dikembangkan [3], [6], [13], [14].

Respon transien hasil tuning PID controller dan FLC dibandingkan [17], [18]. Hal ini dimaksudkan untuk melihat kinerja controller pada obyek yang sama. Penggabungan FLC dan PID controller [3], [19] menghasilkan performa sesuai dengan target respon transien, tetapi strukturnya berbeda. Struktur Fu zzy PID controller dalam seri susunannya masterslave [20]. Struktur paralel Fuzzy PID controller menempatkan FLC sebagai adaptive controller dengan PID controller sebagai obyek tuning [21] - [23].

Peneliti [24] telah mengembangkan model Fuzzy PID controller yang diperoleh dari konversi PID controller menjadi sebuah FLC. Fuzzy PID controller ini merupakan FLC dengan tiga input dan satu output. Struktur Fuzzy PID controller [24] lebih sederhana dibanding model Fuzzy PID controller [3], [19] - [23]. Strukturnya memiliki input yang sama seperti PID controller. Fuzzy PID controller [24] memiliki ekuivalen dengan PID controller. Kedua controller memiliki hubungan linier dan kesetaraan.

Pada riset sebelumnya [24], MF dari Fuzzy PID controller telah dilakukan pengaturan dari bentuk uniform ke ununiform. Output sistemnya menunjukkan adanya perubahan respon transien. Sesuai ke hasil riset [24], peneliti [25] juga telah menyimulasikan Fuzzy PID controller untuk pengaturan kecepatan putaran motor DC. Hasil akhir risetnya adalah sebuah rancangan optimal fuzzy controller. Tuning Fuzzy PID controller [25] dilakukan dengan mengatur interval OR dan mengubah bentuk MF. Teknik tuning dengan pengaturan OR dioptimalkan dengn metode Genetic Algorithm (GA). Hasil output sistemnya menunjukkan respon transien yang optimal, namun amplitudo sinyal outputnya mencapai lebih dari $1500 \mathrm{~V}$ [25].

Berdasarkan permasalahan yang telah dijelaskan, fokus penelitian adalah teknik tuning pada Fuzzy PID controller. Metodenya dengan pengaturan OR dari MF terhadap respon transien sistem dengan memperhatikan amplitudo sinyal output controller. Pengaturanan OR dari MF belum banyak diteliti dan penting untuk ditelusuri implementasinya. Sistem orde tiga berbentuk Persamaan Difernsial ini menjadi obyek teoritis yang dikontrol dengan Fuzzy PID. Bentuk input MF fuzzy adalah segitiga dengan output singleton, sesuai tipe FLC Sugeno. Kemudian respon transien dari output sistem Fuzzy PID controller dibandingkan dengan Fuzzy-PD controller dan PID controller. Hasil riset awal dalam artikel ini untuk mendukung penelitian selanjutnya, yaitu mengimplementasikan Fuzzy PID controller pada Brushless Direct Current Motor (BLDC).

\section{METODE}

Sistem yang digunakan dalam penelitian ini adalah persamaan differesial orde tiga yang telah digunakan dengan PID controller. Persamaan transfer function $\mathrm{G}_{\mathrm{p}}(\mathrm{s})$ pada (1) sebagai pendekatan optimal komputasi hasil Transformasi Lapalce pada desain PID controller.

$$
G_{p}(s)=\frac{1,2}{0,36 s^{3}+1,86 s^{2}+2,5 s+1}
$$

\section{A. PID Controller}

PID controller merupakan penjumlahan paralel dari tiga gain seperti terlihat di Gambar 1 dan repesentasi persamaannya dinyatakan dalam (2).

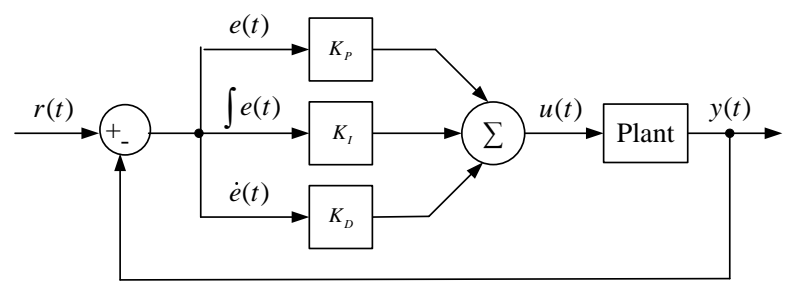

Gambar 1. Struktur PID controller

$$
u(t)=K_{P} e(t)+K_{I} \int e(t)+K_{D} \frac{d e(t)}{d t}
$$

Dengan $\mathrm{u}(\mathrm{t})$ adalah output controller, $e(t)$ adalah sinyal error, $\int e(t)$ adalah integral error, dan $\frac{d e(t)}{d t}$ adalah derivative error. $\mathrm{K}_{\mathrm{P}}$ adalah proportional gain, $\mathrm{K}_{\mathrm{I}}$ adalah integral gain, $\mathrm{K}_{\mathrm{D}}$ adalah differential gain.

\section{B. Fuzzy Logic Controller}

Penyelesaian permasalahan-permasalahan pada sistem linier maupun nonlinier seringkali menggunakan control cerdas, salah satunya FLC. Cara mendesain FLC, semua masukkan real sistemnya dikonversi ke dalam variabel linguistik. Hasil konversinya disimpan di dalam knowledgebase fuzzy dan proses konversinya disebut fuzzifikasi. Mesin inference fuzzy berupa "IF-THEN" [26], merupakan aturan fuzzy yang memproses set-set input fuzzy menjadi sinyal output fuzzy. Selanjutnya output fuzzy dikembalikan ke bentuk real melalui proses defuzifikasi.

\section{Ekuivalensi antara FLC dan PID Controller}

Input/output dari variabel PID controller seperti pada (1) dapat dimasukkan sebagai variable dalam rancang FLC. Variable output $u(t)$, dan tiga input $e(t), \int e(t)$, dan $\dot{e}(t)$ diasumsikan sebagai OR output/input dari MF. 

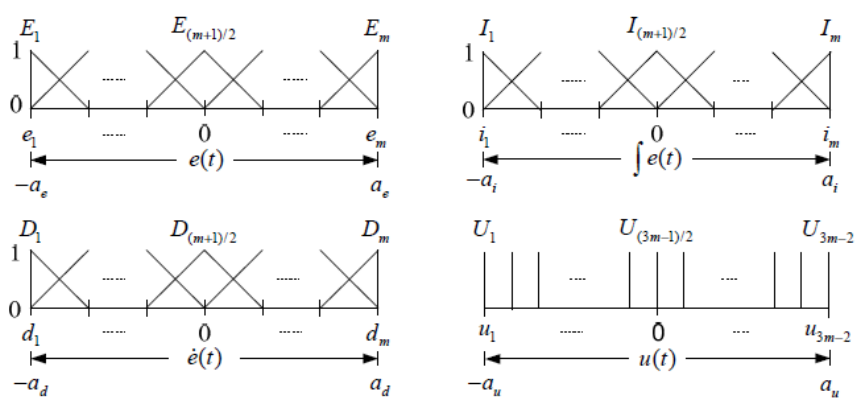

Gambar 2. Pemetaan input/output MF dan variable FLC [24]

Ketiga input dan satu output dari MF dinyatakan berturutturut dalam $O R_{e}=\left[-a_{e}, a_{e}\right], O R_{i e}=\left[-a_{i}, a_{i}\right], O R_{d e}=$ $\left[-a_{d}, a_{d}\right]$, dan $O R_{u}=\left[-a_{u}, a_{u}\right]$ [24]. Jumlah MF masingmasing input adalah $\mathrm{m}$, sedangkan variabel output $u(t)$ yang difuzzifikasi jumlahnya $(3 m-2)$. Gambar 2 menunjukkan bentuk input dan output, serta jumlah MF. Input MF fuzzy berbentuk segitiga, sedangkan outputnya singleton [24]

Tiga variabel input $\left(e(t), \int e(t)\right.$, dan $\left.\dot{e}(t)\right)$ fuzzy rules, dinyatakan dalam kubik FAM, seperti ditunjukkan dalam Gambar 3. Output fuzzy-nya sebagai hasil consequence dan antecedent, yang didefinisikan dalam (3) [24].

$$
\begin{gathered}
\text { IF } e(t) \text { is } E_{i} \text { and } \int e(t) \text { is } I_{j} \text { and } \dot{e}(t) \text { is } D_{k} \\
\text { THEN } u(t) \text { is } U_{l} \\
l=i+j+k-2
\end{gathered}
$$

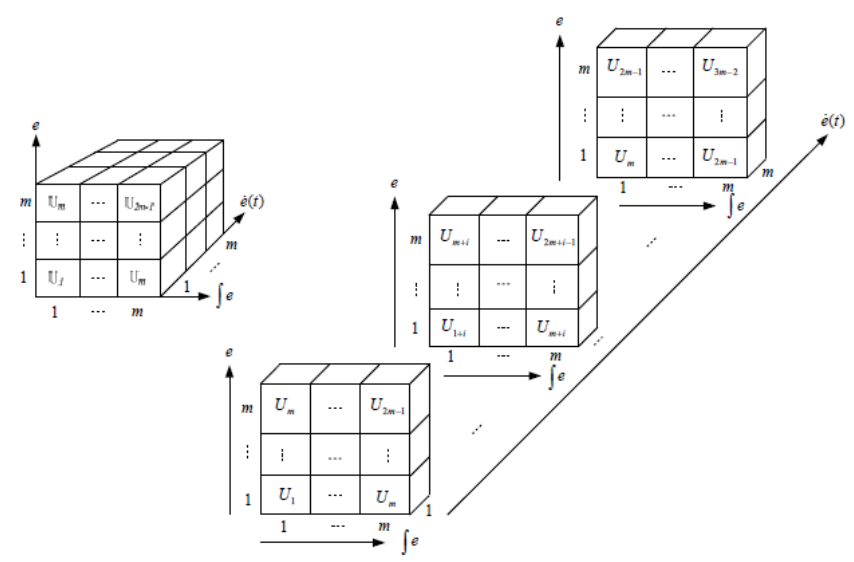

Gambar 3. Irisan kubik dari FAM [24]

Detail uraian dan penurunan dari fuzzy rule dijelaskan dalam riset sebelumnya [24]. Sehingga kesesuaian persamaan output $u(t)$ FLC dinyatakan dalam (4).

$$
u(t)=\frac{a_{u}}{3 a_{e}} e(t)+\frac{a_{u}}{3 a_{i}} \int e(t)+\frac{a_{u}}{3 a_{d}} \frac{d e(t)}{d t}
$$

Dengan $a_{e}$ adalah range error, $a_{i}$ adalah range integral error, $a_{d}$ adalah range differential error, dan $a_{u}$ adalah range output.

Persamaan (4) sesuai dengan (2) dan menunjukkan bahwa PID controller ekuivalen dengan FLC [24]. Dengan demikian PID controller dapat dikonversi ke dalam bentuk FLC. Konversi in i melibatkan kedua variabel pengendali, yaitu gain PID controller $\left(K_{P}, K_{I}, K_{D}\right)$ dan OR dari MF input/output fuzzy $\left(a_{e}, a_{i}, a_{d}\right.$, dan $\left.a_{u}\right)$. Variable-variabel tersebut merepresentasikan amplitudo untuk sinyal-sinyal error integral error, derivative error, dan output. Fungsi persamaan konversi antara PID controller dan FLC ditunjukkan pada (5). Sementara bentuk struktur FLC hasil konversi dengan PID controller ditunjukkan pada Gambar 5 .

$$
K_{p}=\frac{a_{u}}{3 a_{e}}, \quad K_{I}=\frac{a_{u}}{3 a_{i}}, \quad K_{p}=\frac{a_{u}}{3 a_{d}}
$$

\section{Desain Controller}

FLC yang dibahas terdiri dari Fuzzy PD controller dan Fuzzy PID controller. Input Fuzzy PD controller terdiri dari $e(t)$ dan $\dot{e}(t)$ dan outputnya $u(t)$. Sedangkan input Fuzzy PID controller terdiri dari $e(t), \int e(t)$, dan $\dot{e}(t)$, serta outputnya $u(t)$. Strukturnya seperti ditunjukkan pada Gambar 4. Sementara untuk Fuzzy PID controller strukturnya ditunjukkan pada Gambar 5.

\begin{tabular}{|c|c|c|c|c|c|}
\hline & 1 & 2 & 3 & 4 & 5 \\
\hline & 1 & 2 & 3 & 4 & 5 \\
\hline & 2 & 3 & 4 & 5 & 6 \\
\hline & 3 & 4 & 5 & 6 & 7 \\
\hline 4 & 4 & 5 & 6 & 7 & 8 \\
\hline & 5 & 6 & 7 & 8 & 9 \\
\hline
\end{tabular}

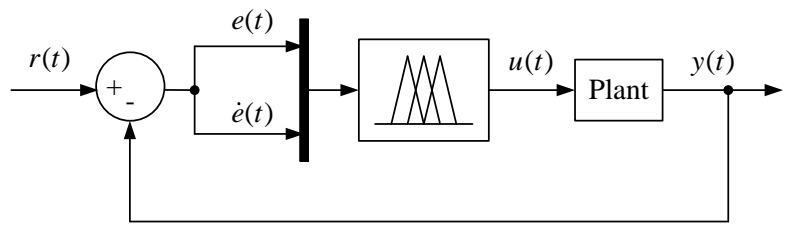

Gambar 4. Struktur Fuzzy PD controller

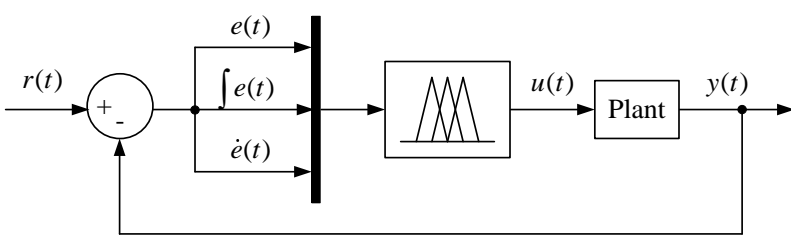

Gambar 5. Struktur Fuzzy PID controller [24]

\section{Gambar 6. FAM Fuzzy PD controller}

Gambar 6 menunjukkan FAM Fuzzy PD controller dengan dua input satu output. Jumlah MF masing-masing input dipilih 5. Alasan pemilihan jumlah tersebut adalah pertimbangan waktu komputasi.

Input MF dinyatakan dengan notasi 1, 2, 3, 4, 5, sedangkan outputnya $1,2,3,4,5,6,7,8$, dan 9 . Formula perhitungan variabel ouputnya atau $u(t)$ untuk 2 input adalah $(2 m-1)$. Penggunaan notasi-notasi tersebut dimaksudkan untuk me mudahkan penulisan FAM. Total fuzzy rules untuk 2 input MF yang berjumlah 5 adalah 25 . Hal yang sama juga berlaku untuk FAM Fuzzy PID controller. Jumlah total fuzzy rules untuk 3 input MF yang berjumlah 5 adalah 125. Formula perhitungan variabel ouputnya atau $u(t)$ untuk 3 input adalah 
(3m - 2). Bentuk FAM untuk Fuzzy PID controller ditunjukkan pada Gambar 7.

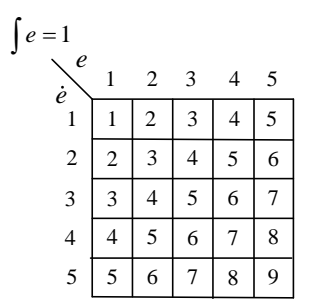

$$
\begin{aligned}
& \int e=2
\end{aligned}
$$

\begin{tabular}{|c|c|c|c|c|c|c|c|c|c|c|c|c|c|c|c|c|c|}
\hline \multicolumn{18}{|l|}{$\int e=3$} \\
\hline & 1 & 2 & 3 & 4 & 5 & $\grave{e}$ & 1 & 2 & 3 & 4 & 5 & 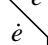 & 1 & 2 & 3 & 4 & 5 \\
\hline 1 & 3 & 4 & 5 & 6 & 7 & 1 & 4 & 5 & 6 & 7 & 8 & 1 & 5 & 6 & 7 & 8 & 9 \\
\hline 2 & 4 & 5 & 6 & 7 & 8 & 2 & 5 & 6 & 7 & 8 & 9 & 2 & 6 & 7 & 8 & 9 & 10 \\
\hline 3 & 5 & 6 & 7 & 8 & 9 & 3 & 6 & 7 & 8 & 9 & 10 & 3 & 7 & 8 & 9 & 10 & 11 \\
\hline 4 & 6 & 7 & 8 & 9 & $\mid 10$ & 4 & 7 & 8 & 9 & 10 & 11 & 4 & 8 & 9 & 10 & 11 & 12 \\
\hline 5 & 7 & 8 & 9 & 10 & 11 & 5 & 8 & 9 & 10 & 11 & 12 & 5 & 9 & 10 & 11 & 12 & 13 \\
\hline
\end{tabular}

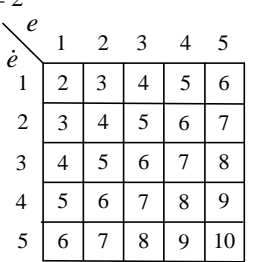

Gambar 7. FAM Fuzzy PD controller

\section{HASIL DAN PEMBAHASAN}

Sistem orde tiga dengan PID controller ditunjukkan pada Gambar 8. Tuning PID controller disimulasikan dengan metode kedua Ziegler-Nichols. Pencarian critical gain $\left(\mathrm{K}_{\mathrm{cr}}\right)$ dilakukan sampai output sistemnya mengalami osilasi dan terlihat periodenya $\left(\mathrm{P}_{\mathrm{cr}}\right)$. Kedua nilai $\mathrm{K}_{\mathrm{cr}}$ dan $\mathrm{P}_{\mathrm{cr}}$ digunakan untuk mengkonversi ke $K_{P}, T_{i}$, dan $T_{d}$. Akhirnya diperoleh nilai $K_{P}=6, K_{I}=5,04$, dan $K_{D}=1,785$.

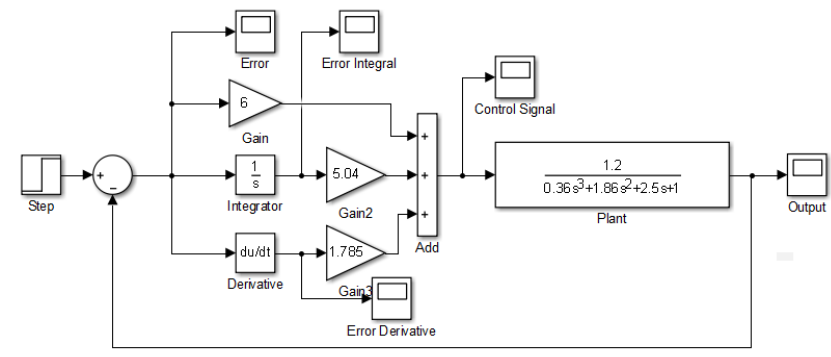

Gambar 8. PID controller pada sistem orde tiga

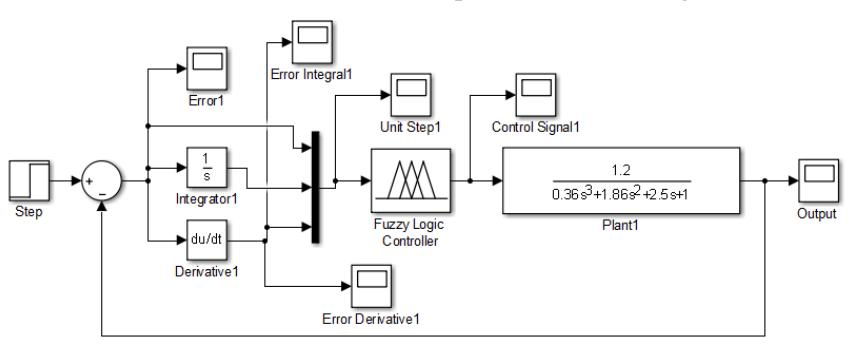

Gambar 9. Fuzzy PID controller hasil konversi

Konversi PID controller ke FLC, digunakan (5). Nilai $a_{e}$ didapat dari hasil pengukuran amplitudo sinyal error pada Gambar 8. A mplitudo sinyal error terukur sebesar 8. Dengan demikian diperoleh nilai-nilai $a_{e}=8, a_{i}=9,52, a_{d}=26,89$, dan $a_{u}=144$. Gambar 9 adalah bentuk rangkaian Fuzzy PID controller hasil konversi dengan PID controller.

Sinyal keluaran dari sistem menunjukkan sebuah kesetaraan antara sinyal PID controller dengan sinyal Fuzzy PID controller, seperti ditunjukkan pada Gambar 10. Sinyal
Fuzzy PID controller (warna merah) menutupi sinyal PID controller (warna hijau) dan kedua sinyal tersebut adalah identik.

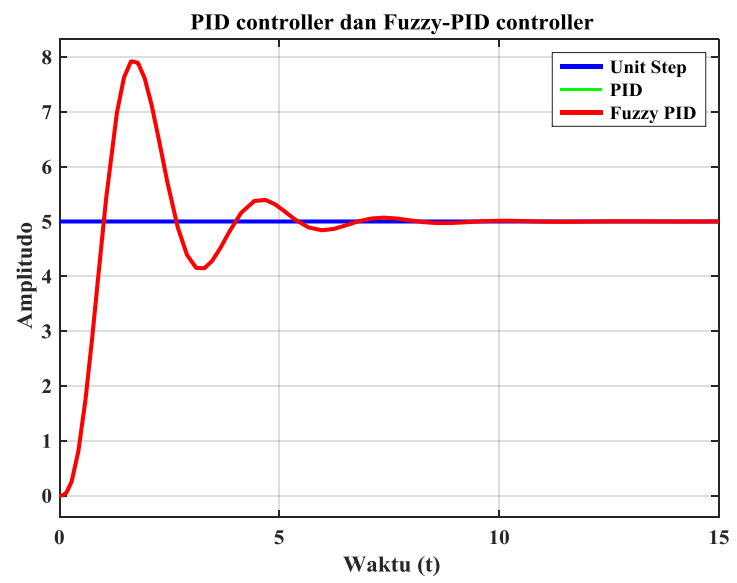

Gambar 10. Sinyal respon transien keluaran sistem PID controller dan Fuzzy PID controller.

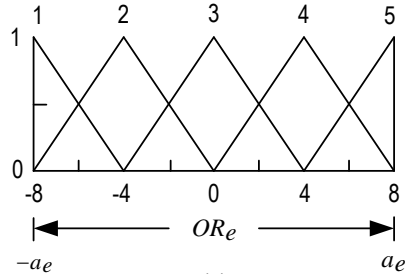

(a)

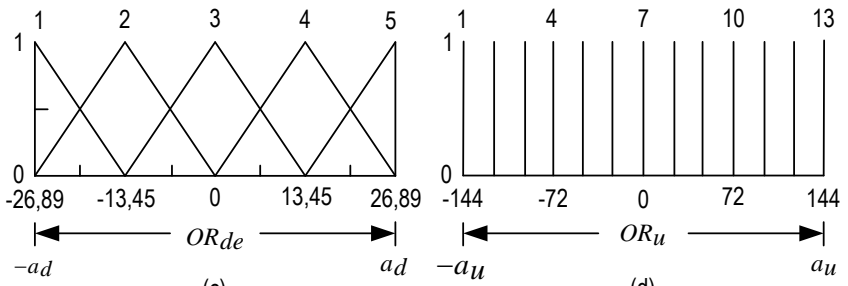

(c)

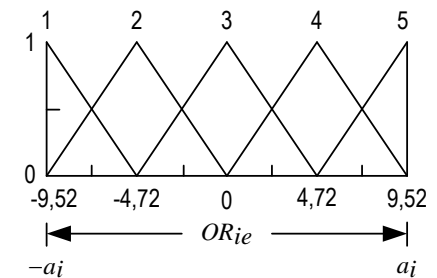

(b)

(d)
Gambar 11. Input dan output MF pada Fuzzy PID controller

Bentuk MF Fuzzy PID controller untuk ketiga input $\left(a_{e}\right.$, $a_{i}$, dan $a_{d}$ ) berupa segitiga ditunjukkan pada Gambar 11 (a), 11 (b), dan 11 (c). Nilai OR dari MF untuk input fuzzy berturut-turut $\mathrm{OR}_{\mathrm{e}}=(-8,8), \mathrm{OR}_{\mathrm{ie}}=(-9,52,952)$, dan $\mathrm{OR}_{\mathrm{de}}=(-$ 26,89, 26,89). Sedangkan bentuk MF output fuzzy berupa fuzzy singleton yang ditunjukkan pada Gambar 11 (d). Nilai jangkauan operasi untuk fungsi keanggotaan keluaran fuzzy $\mathrm{OR}_{\mathrm{u}}=(-144,144)$.

Hubungan ketiga input terhadap output fuzzy ditunjukkan pada Gambar 12 berbentuk surface view. Tampilan surface view datar yang menunjukkan bahwa ruang lingkup FLC lin ier.

Perbaikan respon transien Fuzzy PID controller pada Gambar 10, dengan mengatur interval OR pada MF input. Nilai OR dari ke tiga input MF fuzzy $\left(a_{e}, a_{i}\right.$, dan $\left.a_{d}\right)$ diatur menjadi besar atau kecil. Pengaturan nilai OR.dilakukan hingga respon transien sesuai set point. Teknik tuning ini dilakukan secara coba-coba (trial and error). Sementara interval OR pada output MF fuzzy $\left(a_{u}\right)$ dibuat tetap yaitu sebesar $\mathrm{OR}_{\mathrm{u}}=(-144,144)$. 


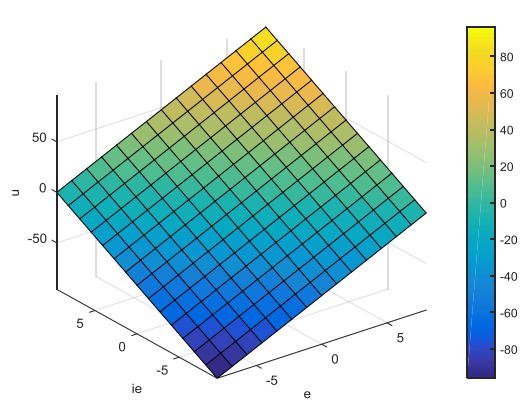

Gambar 12. Tampilan surface view Fuzyy-PID controller

Perubahan nilai OR dari MF ouput berpengaruh terhadap amplitudo sinyal ouput controller. Sinyal output contoller dibahas pada artikel berikutnya, artikel ini hanya membahas OR dari MF input. Bentuk input MF fuzzy hasil tuning untuk Fuzzy PID controller ditunjukkan pada Gambar 13 (a), 13 (b), 13 (c). Nilai OR pada input MF fuzzy setelah proses tuning masing-masing adalah $\mathrm{OR}_{\mathrm{e}}=(-10,10), \mathrm{OR}_{\mathrm{ie}}=(-48,48)$, dan $\mathrm{OR}_{\mathrm{de}}=(-20,20)$. Sedangkan nilai $\mathrm{OR}$ dari output MF fuzzy dibuat tetap pada $\mathrm{OR}_{\mathrm{u}}=(-144,144)$ dalam bentuk singleton, seperti ditunjukkan pada Gambar 13 (d). Hasil tampilan permukaan setelah tuning pada Fuzzy PID controller ditunjukkan pada Gambar 14.

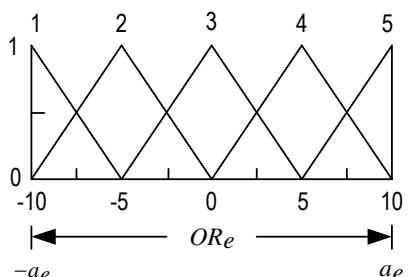

(a)

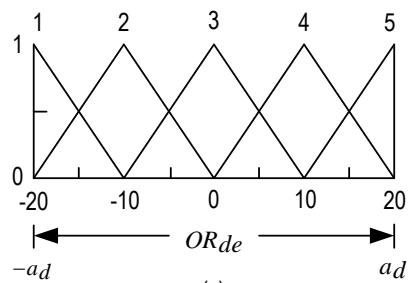

(c)

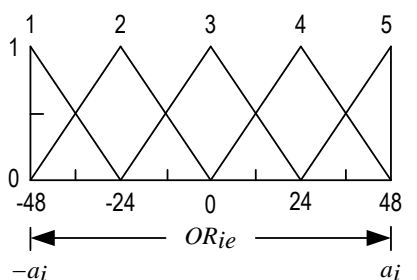

(b)

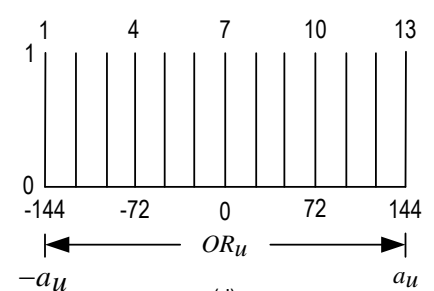

(d)

Gambar 13. Input dan output MF fuzzy pada Fuzzy PID controller

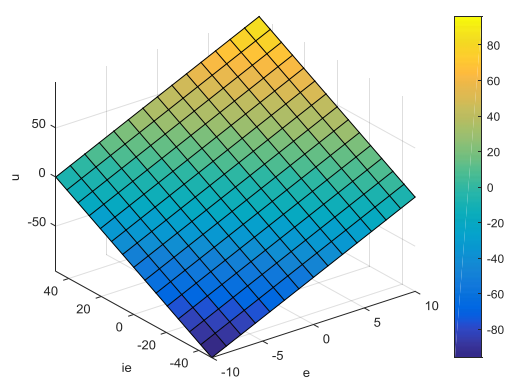

Gambar 14. Tampilan surface view Fuzyy-PID controller
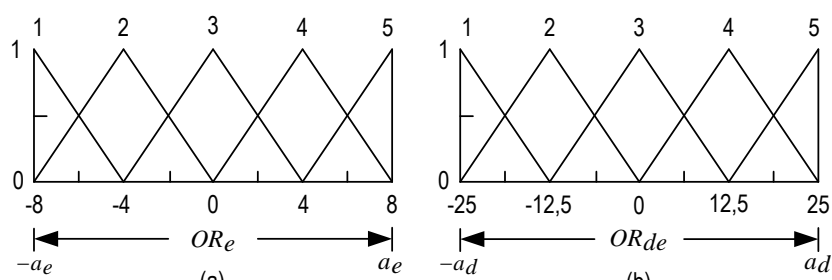

(b)

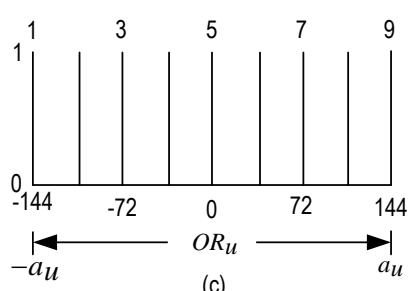

(c)

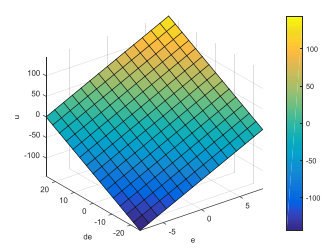

(d)

Gambar 15. Gambar input/output MF Fuzzy dan surface view

Selanjutnya untuk Fuzzy PD controller, diberlakukan teknik tuning yang sama seperti pada Fuzzy PID controller. Rancangan Fuzzy PD controller tidak melibatkan nilai $a_{i}$. Nilai OR setelah tuning pada input MF fuzzy adalah $\mathrm{OR}_{\mathrm{e}}=(-8$, 8), dan $\mathrm{OR}_{\mathrm{de}}=(-25,25)$. Sedangkan nilai $\mathrm{OR}$ untuk $\mathrm{MF}$ keluaran Fuzzy PID adalah tetap sebesar $\mathrm{OR}_{\mathrm{u}}=(-144,144)$.

Bentuk MF fuzzy masing-masing input ditunjukkan pada Gambar 15 (a) dan 15 (b). Gambar 15 (c) adalah bentuk output MF-nya berupa fuzzy singleton. Sedangkan Gambar 15 (d) adalah bentuk dari tampilan permukaan yang merupakan representative dari gabungan antara input dan output fuzzy. Sinyal respons transien hasil tuning untuk PID controller, Fuzzy PD controller, dan Fuzzy PID controller ditunjukkan pada Gambar 16.

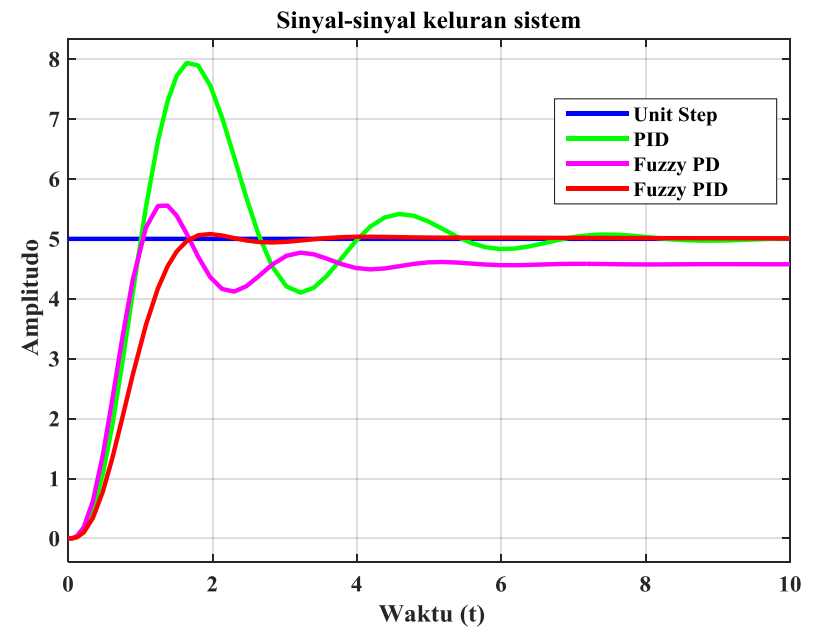

Gambar 16. Sinyal-sinyal keluaran sistem pada PID controller, Fuzzy PD controller, dan Fuzzy PID controller

Respon keluaran sistem PID controller, untuk rise time $\mathrm{T}_{\mathrm{r}}$ lebih cepat diawal yaitu $0,60 s$ namun memiliki Percent Overshoot (PO) yang paling tinggi sebesar 58,9\% dan mencapai settling time $\left(\mathrm{T}_{\mathrm{s}}\right)$ lebih lama sebesar $6,49 \mathrm{~s}$ dengan error steady state $\left(\mathrm{E}_{\mathrm{ss}}\right)$ mencapai nol. Sebaliknya Fuzzy PD controller, mampu mengurangi $\mathrm{PO}$ sebesar 47,8\% dan memperbaiki $\mathrm{T}_{\mathrm{s}}$ sebesar 1,30 s namun nilai offset atau $\mathrm{E}_{\mathrm{ss}}$ sebesar 0,42. Hal ini disebabkan karena Fuzzy PD controller 
tidak memiliki Integral controller. Sementara itu, pada Fuzzy PID controller mampu meredam nilai PO hingga 1,3\% dan me miliki $\mathrm{T}_{\mathrm{s}}$ yang paling cepat sebesar 1,60 s dengan nilai $\mathrm{E}_{\mathrm{ss}}=$ 0 . Namun demikian, untuk $\mathrm{T}_{\mathrm{r}}$ tidak secepat PID controller maupun Fuzzy PD controller yaitu sebesar 0,97s. Rangku man respon transien keluaran sistem dari ketiga controller ditunjukkan pada Tabel I.

TABEl I. PERbedaAn Respon TRANSIEN PENGENdali

\begin{tabular}{|c|c|c|c|c|}
\hline Controller & $\begin{array}{c}\boldsymbol{T r}(\mathbf{s}) \\
\mathbf{1 0 \%} \mathbf{9 0 \%}\end{array}$ & $\begin{array}{c}\boldsymbol{T s}(\mathbf{s})= \\
\mathbf{\mathbf { 2 \% }}\end{array}$ & $\begin{array}{c}\boldsymbol{P O} \\
\mathbf{( \% )}\end{array}$ & $\boldsymbol{E}_{\boldsymbol{s}}$ \\
\hline PID & 0,60 & 6,49 & 58,94 & 0 \\
\hline Fuzzy PD & 0,62 & 5,19 & 11,10 & 0,42 \\
\hline Fuzzy PID & 0,97 & 1,60 & 1,26 & 0 \\
\hline
\end{tabular}

Gambar 17 menunjukkan sinyal output dari ketiga model controller. Fuzzy PID controller me mpunyai amplitudo sinyal control paling kecil sebesar 24,12. Namun sebaliknya, Fuzzy PD controller mempunyai amplitudo sinyal output control paling besar yaitu 45,00. Sedangkan sinyal output PID controller amplitudonya sebesar 32,53. Ini berarti bahwa Fuzzy PID controller memiliki energi yang lebih hemat dan lebih efisien dibanding PID controller dan Fuzzy PD controller. Rangkuman tentang amplitudo sinyal output controller ditunjukkan pada Tabel II.

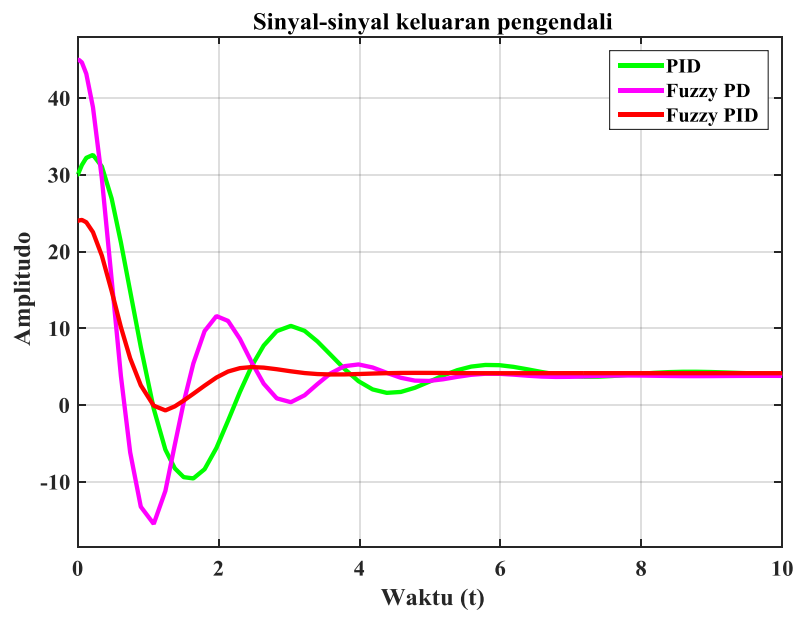

Gambar 17. Sinyal output dari beberapa controller

TABEL II. Respons Siny Al Keluaran Tiga Model Pengendali

\begin{tabular}{|c|c|}
\hline Pengendali & Amplitudo sinyal keluaran kendali \\
\hline PID & 32,53 \\
\hline Fuzzy PD & 45,00 \\
\hline Fuzzy PID & 24,12 \\
\hline
\end{tabular}

Berdasarkan simulasi, hasil konversi antara PID controller dengan Fuzzy PID controller menunjukkan kesetaraan. Kedua sinyal menunjukan identik. Setelah proses tuning pada Fuzzy PID controller, respon transien sistem menunjukkan perbaikan. Nilai $\mathrm{T}_{\mathrm{s}}$ PID controller telah diperbaiki oleh Fuzzy PID controller hingga 75,3\% dan PO berkurang hingga 57,7\%. Sementara hasil tuning Fuzzy PD controller tidak menunjukkan perbaikan signifikan respons transien seperti pada Fuzzy PID controller. Hasilnya menunjukkan bahwa respon transien Ts PID controller diperbaiki hanya 20,0\% dan PO-nya berkurang 47,8\%.

Teknik tuning OR MF input pada Fuzzy PID controller mampu memperbaiki respon transien dari PID controller. Data di Tabel I dan Tabel II, Fuzzy PID controller menunjukkan keunggulan dibandingkan kedua controller tersebut.

\section{PENUTUP}

Pengembangan metode tuning Fuzzy PID berbasis PID controller terhadap sistem orde tiga metode pengaturan OR telah berhasil. Dari hasil simu lasi terbukti bahwa Fuzzy PID controller unggul dibandingkan Fuzzy PD controller dan PID controller. Keunggulan dimaksud pada respon transiennya lebih cepat, yang ditunjukkan dengan perbaikan Ts hingga $75,3 \%$ dan PO. berkurang sebesar $57,7 \%$. Perubahan Ts dan PO pada Fuzzy PID tersebut menggunakan pembanding PID Controller. Selain itu, amplitudo lebih rendah yaitu Fuzzy PID: PID controller adalah 24,12:32,53. Nilai-nilai PO, Ts, dan amplitudo tersebut menunjukkan bahwa performa Fuzzy PID dengan teknik tuning pengaturan OR dan MF lebih baik dibandingkan dengan PID controller. Hasil penelitian ini dapat mendasari penelitian selanjutnya, yaitu mengimplemetasikan Fuzzy PID pada BLDC.

\section{REFERENSI}

[1] A. H. Halim and I. Ismail, "Tree Physiology Optimization tuning rule for Proportional-Integral control," in MATEC Web of Conferences, 2017, vol. 131,p. 3018.

[2] Z. Salleh, M. Sulaiman, and R. Omar, "Tuning fuzzy membership functions to improve performance of vector control induction motor drives," J. Telecommun. Electron. Comput. Eng., vol. 8, no. 2, pp. 1-4, 2016.

[3] J. Yin, D. Zhu, J. Liao, G. Zhu, Y. Wang, and S. Zhang, "Automatic Steering Control Algorithm Based on Compound Fuzzy PID for Rice Transplanter,"Appl. Sci., vol. 9, no. 13, p.2666, 2019.

[4] Y. Qin, L. Sun, Q. Hua, and P. Liu, "A fuzzy adaptive PID controller design for fuel cell power plant," Sustainability, vol. 10, no. 7, p. 2438, 2018.

[5] W. Hao and J. Kan, "Application of self-tuning fuzzy proportionalintegral-derivative control in hydraulic crane control system," $A d v$. Mech. Eng., vol. 8, no.6, p. 1-10,2016.

[6] W. Gubara, M. Elnaim, and S. F. Babiker, "Comparative study on the speed of DC motor using PID and FLC," in 2016 Conference of Basic Sciences and Engineering Studies (SGCAC), 2016,pp.24-29.

[7] O. Ibrahim, S. A. Y. Amuda, O. O. Mohammed, and G. A. Kareem, "Performance Evaluation of three PID Controller T uning Algorithm on a process plant," Int. J. Electr. Comput. Eng., vol. 5, no. 5, 2015.

[8] N. Allu and S. Salu, "Aplikasi Penalaan Dengan Metode Ziegler Nichols di Perancangan Penpendali PID pada Putaran Motor DC," in Prosiding Seminar Nasional Sinergitas Multidisiplin Imu Pengetahuan dan Teknologi, 2018, vol. 1,pp. 203-207.

[9] R. Kumar, S. K. Singla, and V. Chopra, "Comparison among some well known control schemes with different tuning methods," J. Appl. Res. Technol., vol. 13, no.3, pp. 409-4015, 2015.

[10] J. M. S. Ribeiro, M. F. Santos, M. J. Carmo, and M. F. Silva, "Comparison of PID controller tuning methods: analytica/classical techniques versus optimization algorithms," in 2017 18th intemational Carpathian control conference (ICCC), 2017, pp.533-538.

[11] N. Pitalúa-Díaz, E. J. Herrera-López, G. Valencia-Palomo, A. González-Angeles, R. A. Rodríguez-Carvajal, and N. R. CazarezCastro, "Comparative Analysis between Conventional PI and Fuzzy LogicPI Controllers for Indoor Benzene Concentrations," Sustainability, vol. 7, no. 5, pp. 5398-5412, 2015. 
[12] D. O. Njoku, A. O. Agbakwuru, I. A. Amaefule, and I. S. Onyema, "Application and Implementation of Fuzzy Logic Controller (FLC) for Feed Chemical Concentration Process," transport, vol. 2, pp. 16-19, 2018.

[13] F. A. Bakri, M. Y. Mashor, S. M. Sharun, S. N. B. Sarpinah, and Z. A. Bakar, "Adaptive fuzzy logic controller with direct action type structures for InnoSAT attitude control system," in IOP Conference Series: Materials Science and Engineering, 2016, vol. 152, no. 1, p. 12032.

[14] J. A. Bala, O. M. Olaniyi, T. A. Folorunso, and O. T. Arulogun, "Poultry Feed Dispensing System Control: A Case between Fuzzy Logic Controller and PID Controller," Balk. J. Electr. Comput. Eng., vol. 7, no. 2, pp. 171-177, 2019.

[15] V. T. Aghaei and A. Onat, "Tuning scaling factors of fuzzy logic controllers via reinforcement learning policy gradient algorithms," in Proceedings of the $3 \mathrm{rd}$ International Conference on Mechatronics and Robotics Engineering, 2017, pp. 146-151.

[16] W. Gritli, H. Gharsallaoui, and M. Benrejeb, "PID-type fuzzy scaling factors tuning using genetic algorithm and simulink design optimization for electronic throttle valve," in 2016 Intemational Conference on Control, Decision and Information Technologies (CoDIT), 2016, pp. 216-221.

[17] A. M. Najar and D. K. Arif, "Comparison between PID controller and fuzzy sliding mode control (FSMC) on super heater system," in Journal of Physics: Conference Series, 2019, vol. 1218, no. 1, p. 12055.

[18] A. Kharidege, D. Jianbiao, and Y. Zhang, "Performance Study of PID and Fuzzy Controllers for Position Control of 6 DOF arm Manipulator with Various Defuzzification Strategies," in MATEC Web of Conferences, 2016, vol. 77, p. 1011.

[19] J. Dong and B. He, "Novel fuzzy PID-type iterat ive learning control for quadrotor UAV," Sensors, vol. 19, no. 1, p. 24, 2019.

[20] A. Pappachen and A. P. Fathima, "BFOA based FOPID controller for multi area AGC system with capacitive energy storage," Int. J. Electr. Eng. Informatics, vol. 7, no. 3, p. 429, 2015

[21] Z. Chen and J. Qu, "Control of suspended low-gravity simulation system based on self-adaptive fuzzy PID," in IOP Conference Series: Materials Science and Engineering, 2017, vol.231, no. 1,p. 12070.

[22] Y. Tao et al., "Fuzzy PID control method of deburring industrial robots," J. Intell. Fuzzy Syst., vol. 29, no. 6, pp. 2447-2455, 2015.

[23] S. Zhang, Y. Zhang, X. Zhang, and G. Dong, "1888. Fuzzy PID control of atwo-link flexible manipulator.," J. Vibrengineering, vol. 18, no. 1, 2016.

[24] C.-T. Chao, N. Sutarna, J.-S. Chiou, and C.-J. Wang, "Equivalence between fuzzy PID controllers and convent ional PID controllers," Appl. Sci., vol. 7, no. 6, p. 513, 2017.

[25] C.-T. Chao, N. Sutarna, J.-S. Chiou, and C.-J. Wang, "An Optimal Fuzzy PID Controller Design Based on Conventional PID Control and Nonlinear Factors," Appl. Sci., vol. 9, no. 6, p. 1224, 2019.

[26] K. Yan and H. Mo, "Application of fuzzy control under time-varying universe in unmanned vehicles," in 2018 33rd Youth Academic Annual Conference of Chinese Association of Automation (YAC), 2018, pp. 439-444. 